\title{
Impactos de investimentos em infraestruturas rodoviárias sobre o desenvolvimento regional no Brasil - possibilidades e limitações
}

\author{
Mauricio Oliveira Andrade ${ }^{1}$, Maria Leonor Alves Maia ${ }^{2}$ e Oswaldo Cavalcanti da Costa Lima Neto ${ }^{3}$
}

\begin{abstract}
Resumo: Este artigo objetiva analisar as possibilidades e as limitações dos impactos produzidos por investimentos em infraestruturas rodoviárias sobre o crescimento econômico em nível local e regional. A discussão está apoiada em conceitos e experiências relatadas na literatura sobre as relações entre infraestruturas de transportes rodoviários e a dinâmica econômica regional, sob a ótica da economia espacial, mais especificamente sobre a teoria da decisão da localização de empresas; e sob a abordagem da economia dos transportes, que relaciona o tráfego gerado e induzido com as atividades econômicas. Como objeto empírico foram analisados os resultados, em nível regional, dos efeitos da duplicação da BR-232-PE, trecho RecifeSão Caetano com 150 km de extensão, aberta ao tráfego em 2004, com período de avaliação até o final de 2010. As conclusões enfatizam a capacidade das infraestruturas rodoviárias em impactar positivamente na região diretamente beneficiada com relação ao crescimento da produção agregada, à geração de empregos, à abertura de novas empresas e ao crescimento da massa salarial. No entanto, observa-se também, que este projeto não foi capaz de: (i) produzir um crescimento equilibrado na região; (ii) alterar as relações hierárquicas entre as cidades; (iii) estimular a distribuição da renda; e (iv) ajudar a promover a sustentabilidade fiscal no nível das finanças públicas dos municípios beneficiados.

Palavras-chave: infraestruturas para o desenvolvimento regional, transporte rodoviário, impactos econômicos de rodovias.
\end{abstract}

\begin{abstract}
This paper aims to analyze the possibilities and limitations of the impacts produced by investments in road infrastructure on economic growth at local and regional level. The discussion is based on concepts and cases reported in the literature on the relationship between road transport infrastructure and the dynamics of the regional economy, from the perspective of spatial economics, more specifically on the theory of business location decision; and under the approach of transport economics, which relates the generated and induced traffic with economic activities. The empirical study refers to the effect, at the regional level, of the duplication of BR 232-PE, from Recife to São Caetano, $150 \mathrm{~km}$ of road extension, opened to traffic in 2004, with an assessment period until the end of 2010. The findings emphasize the capacity of road infrastructure to positively impact the directly benefited region, with respect to aggregate output growth, job generation, opening new businesses and the growth of wages. However, it is also observed that this project has been unable to: (i) produce a balanced growth in the region, (ii) alter the hierarchical relationships between cities, (iii) stimulate the redistribution of income; and (iv) help to promote fiscal sustainability in the public finances of the benefited municipalities.
\end{abstract}

Keywords: infrastructures for regional development, road transport, economic impacts of highways.

\section{INTRODUÇÃO}

O desenvolvimento social e o crescimento econômico de uma região demandam consistentes investimentos em sua infraestrutura de transportes. A interface entre esses investimentos e o crescimento econômico regional apresenta amplas ramificações, que se estendem além dos objetivos principais da movimentação de pessoas e mercadorias. A disponibilidade de uma rede rodoviária regional bem desenvolvida tem sido reconhecida como um fator essencial para o desenvolvimento econômico. Por outro lado, rodovias congestionadas, com elevados índices de acidentes ou operando em níveis de serviço próximos às suas capacidades, conduzem a custos de transportes mais elevados para a economia. A partir da deterioração da qualidade da mobili-

\footnotetext{
1 Mauricio Oliveira Andrade, Universidade Federal de Pernambuco. (mauandrade@gmail.com)

2 Maria Leonor Alves Maia, Universidade Federal de Pernambuco. (nonamaia@gmail.com)

3 Oswaldo Cavalcanti da Costa Lima Neto, Universidade Federal de Pernambuco. (oswaldolimaneto@yahoo.com.br)
}

Manuscrito recebido em 28/05/2015 e aprovado para publicação em 08/10/2015

Este artigo é parte de TRANSPORTES v. 23, n. 3, 2015. ISSN: 2237-1346 (online). DOI:10.14295/transportes.v23i3.797 dade regional, as áreas se tornam menos atrativas, a produtividade dos negócios tende a diminuir, são reduzidas as áreas de abrangência dos mercados para seus produtos, prejudicadas as economias de escala e reduzida a produtividade geral da economia.

Vários estudos, como os de Horst e Moore (2003), Iacono e Levinson (2008) e Wiesbrod e Reno (2009), apesar das variações em seus resultados, têm apontado que, em nível microeconômico, investimentos em infraestrutura rodoviária facilitam o crescimento pelo aumento do retorno dos investimentos privados e, em nível macroeconômico, sugerem que economias de escala, efeitos de acessibilidade e redução de custos de transportes podem levar à expansão das áreas de mercado das empresas locais e gerar oportunidades de acesso a mercados mais abrangentes de insumos, tornando possível a diversificação e o aumento da produtividade econômica.

Sob esse enfoque de geração de externalidades positivas, efeitos diretos e indiretos se fundem e se retroalimentam, produzindo benefícios que se disseminam sobre o território objeto da intervenção. Apesar desses benefícios aparentemente evidentes, há ainda lacunas nesses estudos relacionadas à intensidade dos efeitos e à separação da contribuição de outros fatores de desenvolvimento também relevantes. 
Investimentos em infraestruturas rodoviárias apresentam usualmente como objetivo básico a redução dos custos de transportes. Espera-se normalmente, com a consecução desse objetivo estimular o aumento da mobilidade e do potencial de atratividade da área beneficiada com resultados de dinamização econômica, que podem ser medidos pela evolução do PIB, pelo crescimento do emprego, pela atração de novas empresas, pelo aumento da arrecadação tributária, pelo incremento no consumo, pela ampliação do patrimônio e das infraestruturas públicas e privadas e pela valorização da terra, entre outros.

Nesse contexto, este artigo objetiva analisar as possibilidades e as limitações de investimentos em melhoramentos em infraestruturas rodoviárias em promover crescimento econômico em nível regional e local, tomando como caso de estudo os resultados econômicos de 28 cidades do Agreste e da Zona da Mata de Pernambuco, diretamente beneficiadas pela duplicação da BR-232-PE, trecho RecifeSão Caetano com 150 km de extensão (ANDRADE, 2012). Para analisar os efeitos específicos dos melhoramentos em infraestruturas rodoviárias, essas cidades foram comparadas com um conjunto de 20 cidades não beneficiadas por essas melhorias, com perfil socioeconômico e nível de desenvolvimento assemelhado, estruturadas pelo eixo rodoviário da BR-408/PE-090 (154 km), aproximadamente paralelo funcionando em pistas simples.

Nas discussões conceituais são destacadas as relações esperadas entre melhorias em infraestruturas rodoviárias e a dinamização das atividades econômicas, abordandoas sob um enfoque macroeconômico, sob a ótica da economia espacial e sob a economia dos transportes As conclusões se baseiam na comparação entre a região beneficiada e a região de controle, da evolução de indicadores socioeconômicos selecionados; e na quantificação da influência do fator redução nos tempos de viagem, sob aspectos como produtividade e elasticidade dos ganhos econômicos medidos pela evolução do PIB, abertura de empresas e geração de empregos, apenas dos municípios diretamente beneficiados, no período 2004 (ano de abertura) a 2010.

\section{INFRAESTRUTURAS RODOVIÁRIAS E CRESCIMENTO ECONÔMICO}

Em geral, nos meios técnicos responsáveis pelas políticas públicas e pelo planejamento governamental, apresenta-se fortemente consolidada a compreensão de que melhoramentos nas infraestruturas rodoviárias influenciam na ampliação das potencialidades econômicas das regiões, conduzindo a uma distribuição mais eficiente da população, da indústria e da renda. Reforçando essa argumentação, estudos de Horst e Moore (2003) destacam ainda que o nível de qualidade de uma rodovia influencia no desenvolvimento econômico regional ao longo do tempo, ocorrendo maior diversidade econômica nas áreas servidas por rodovias mais rápidas e eficientes. Desta forma, atividades e mobilidade se influenciam mutuamente no tempo e no espaço. As atividades econômicas localizadas espacialmente interagem entre si gerando fluxos funcionais, dos quais se derivam a demanda por transportes e o tráfego, que por sua vez, dependem de variáveis como: população, empregos, renda, produção e consumo, entre outras.
A correlação entre crescimento do tráfego rodoviário e crescimento econômico regional tem sido interpretada como uma forte evidência da ligação entre transporte e economia. Para Martino et al (2005), esse fato é particularmente verdadeiro nos países em desenvolvimento, onde predominam sistemas de comunicações fragmentados, e a relativa ausência de uma rede rodoviária bem desenvolvida atua como restrição ao crescimento. Rodrigue, Contais e Slack (2009) e Iacono e Levinson (2008) destacam que economias ou regiões que dispõem de melhores condições de mobilidade desfrutam de mais oportunidades para o desenvolvimento econômico. O nível de mobilidade regional torna-se, então, um confiável indicador de desenvolvimento e sua importância, em termos macroeconômicos, está associada ao nível de produção, do emprego e da renda; e, em termos microeconômicos, está associada à formação dos custos de produção e ao alcance dos mercados.

Banister e Berechman (2000) destacam que administradores públicos de uma maneira geral tendem a justificar suas decisões sobre investimentos em infraestruturas de transportes com o objetivo principal de reduzir custos de transportes, propiciando o aumento da competitividade, da produtividade econômica e do nível de emprego, com estímulo ao investimento privado, além de promoverem a integração regional e a revitalização econômica de áreas congestionadas ou mal atendidas. Visando captar esses efeitos de investimentos em rodovias, estudos empíricos nos Estados Unidos (EDRG, 2001) identificaram como principais indicadores para medir o crescimento econômico nas áreas afetadas: i) a quantidade de empregos gerados; ii) a média salarial; iii) a abertura de empresas; iv) a produção e a vendas das empresas; v) o crescimento populacional; vi) o investimento de capital público e privado; e vii) os valores das propriedades urbanas e rurais.

Em working paper para o Banco Mundial sobre infraestrutura rodoviária e desenvolvimento econômico, Queiroz e Gautam (1992) demonstraram uma forte correlação positiva entre a extensão per capita da rede rodoviária pavimentada e o PIB per capita de 98 países, embora reconheçam que a direção da causa e efeito, entre o aumento da renda e estoque de rodovias, seja ainda uma questão controversa.

A partir de uma abordagem mais ampla, Wiesbrod e Reno (2009) destacam que os investimentos em transportes podem impactar a economia de forma direta, indireta e induzida. Impactos econômicos são gerados inicialmente a partir da parcela dos investimentos gastos localmente na fase de obras e na operação, acrescidos dos benefícios na mobilidade, que induzem à expansão dos negócios. Como impactos diretos, há os benefícios aos usuários do sistema de transportes. A expansão das atividades econômicas das empresas diretamente beneficiadas induz a mais crescimento, pois estas requerem mais suprimentos e mão de obra de outras empresas não diretamente beneficiadas, que, por sua vez, também aumentam suas aquisições de insumos e mão de obra gerando mais crescimento. Além disso, a renda adicional obtida pelos trabalhadores aumenta o nível de consumo. O estímulo à atividade econômica relacionada às empresas supridoras denomina-se "efeito indireto" e o estímulo à atividade econômica relativa ao aumento da renda e do consumo dos trabalhadores é denominado "efeito induzido”. 
Partindo do pressuposto de que o capital de uma economia é seu estoque de bens reais com o poder de aumentar a produtividade no futuro, Aschauer (1989) realizou estudos macroeconômicos, com base em dados dos Estados Unidos (1949 a 1985), que objetivaram fazer uma conexão entre investimentos em infraestrutura e crescimento do PIB. Esses estudos pioneiros mostraram que a produtividade da economia estava positivamente relacionada com investimentos públicos em infraestruturas, inclusive rodovias, e que o resultado social do transporte era muito mais significativo do que se pensava. Desde então, eles tem influenciado políticas públicas e pesquisas sobre avaliação dos retornos econômicos de investimentos em infraestruturas nos Estados Unidos e no mundo (TONG, 2013).

Ozbay; Ozmen-Ertekin.; Berechman (2007) em estudo realizado em diversos condados de New York e New Jersey desenvolveu modelos para avaliar a relação dinâmica entre PIB e investimentos em infraestrutura rodoviária. Em seu estudo utilizou modelos com interação entre PIB e índice de desemprego, número de empregos, estoque de capital privado e estoque de capital e investimento em rodovias. Nas conclusões obtidas destacam que capitais privados em rodovias apresentam impactos positivos sobre a renda da população, produzem efeitos diretos positivos que transbordam para a vizinhança, mas que tendem a diminuir com a distância e que o nível presente de produtividade de uma localidade depende não apenas dos índices de emprego e de investimento, mas também dos níveis anteriores de produtividade.

Estache e Fay (2007) destacam que há um crescente consenso sobre a percepção de que as infraestruturas geralmente têm influência sobre o crescimento econômico e sobre os custos de produção, apesar de seus impactos parecerem mais significativos em países ou regiões com menor nível de desenvolvimento. No Brasil, Ferreira (1996) verificou uma forte relação positiva entre investimentos públicos em infraestrutura e crescimento econômico no longo prazo, ao calcular elasticidades com valores superiores aos obtidos nos estudos de Aschauer nos Estados Unidos. Em outros estudos, Ferreira e Malliagros (1998), analisando os investimentos públicos entre 1950 e 1995, observaram que a elasticidade-renda dos investimentos em transportes superou os valores relativos a outras infraestruturas, como energia elétrica e telecomunicações, tendo sido mais significativa nos estados menos desenvolvidos.

A correlação entre investimentos de capital em infraestruturas rodoviárias com melhoria na mobilidade regional e no crescimento econômico tem sido compreendida como uma evidência de uma ligação próxima entre o transporte e a economia (SACTRA, 1999). Nesse contexto, a comparação entre indicadores de impacto, antes e depois, pode ajudar a avaliar a relação entre o aumento da eficiência nas infraestruturas de transportes e o crescimento econômico regional.

No entanto, estas hipóteses da influência positiva das infraestruturas de transportes para o desenvolvimento, em vários estudos, como os de Smith (1994), Boanert (1995), Banister e Berechman (2000), Victoria Transport Policy Institute (2009) e Aragão e Pricinote (2009), têm apresentado conclusões que não recomendam generalizações, embora de maneira geral, não contestem a relevância do papel das rodovias para apoiar o crescimento econômico. Apresentam alguns alertas quanto à generalização desses resultados, dentre eles destacam-se: i) não é trivial o estabelecimento de relações quantitativas entre os investimentos em transportes e o crescimento em nível regional ou aumento da competitividade econômica (Smith, 1994); ii) a elasticidade do PIB como resposta a investimentos em transportes pode ser mais atenuada no caso de economias mais desenvolvidas; iii) na sociedade pós-industrial e tecnológica, o papel dos investimentos em transportes para estimular o desenvolvimento não é mais o mesmo (Banister e Berechman, 2000); e, iv) há pouca evidência empírica se os investimentos beneficiam as áreas periféricas ou reforçam o poder dos centros mais desenvolvidos em ampliar mercados (LITMAN: DOHERTY, 2009).

Esses críticos chamam a atenção para o fato de que os efeitos dos investimentos em transportes dependem de um contexto socioeconômico concreto, sendo dificultada a realização de avaliações em regiões que dispõem de uma rede densa de infraestruturas de alta qualidade, onde os retornos marginais são provavelmente decrescentes. Nas regiões em desenvolvimento, o investimento rodoviário pode efetivamente trazer efeito mais sensível, principalmente quando próximas a regiões metropolitanas ou com urbanização mais densa. Em contrapartida, em localidades estagnadas ou deprimidas, pode ocorrer o efeito do esvaziamento, ou seja, elas podem passar a ser abastecidas por outras mais dinâmicas. De modo geral, reforçam que em países em desenvolvimento são vencedoras as regiões que têm uma economia mais desenvolvida ou estão sendo objeto de forte desenvolvimento e investimento, enquanto que as regiões deprimidas poderão ter seu esvaziamento agravado. Diante dessas ressalvas, fica a necessidade de analisar no caso apresentado neste artigo, se os resultados positivos enfatizados no nível regional se materializaram de forma homogênea entre os municípios.

Diante do exposto, fica evidenciada em nível teórico, apesar das diferenças de enfoques, a convergência entre vários pesquisadores, sobre o papel relevante desempenhado pelas infraestruturas de transportes rodoviários na criação de condições favoráveis ao aumento da dinâmica econômica de uma região.

\section{ECONOMIA ESPACIAL E CUSTOS DE TRANSPORTES}

A acessibilidade regional e os custos de transportes, juntamente com fatores sociais, políticos, institucionais e ambientais associados, moldam a distribuição das atividades econômicas sobre os territórios. Para Krugman, (1996) parte significativa do desenvolvimento espacial das cidades e regiões pode ser explicada pela interação entre duas forças motrizes principais: economias de escala e custos de transportes. Todos os tipos de uso do solo experimentam retornos de escala crescentes no nível das economias internas das firmas, por meio da redução de custos do trabalho pela produção em massa; e no nível das economias externas de escala ou das economias de aglomeração, através de sinergias entre empresas e acesso a grandes mercados de trabalho e de consumidores. 
A maioria das teorias pioneiras sobre economia espacial estabelecia o custo de transporte como fator principal nas escolhas de localização. Segundo Fujita et al (2002), a teoria das localizações apresenta pelo menos três grandes vertentes: i). a de von Thünen que provém da análise do aluguel e do uso da terra para a agricultura ; ii) a de Alfred Weber, focada na localização ótima das indústrias com relação aos custos dos fretes; e iii) a da teoria da área central de Christaller e Losch que oferece uma resposta à questão de como as economias de escala se integram para gerar uma economia espacial.

A importância dos transportes para a localização das atividades econômicas também é enfatizada por Rodrigue, Contais e Slack (2009), ao destacarem que em uma economia de mercado, na qual se procura a maximização dos resultados econômicos, a localização é o resultado de decisões, onde múltiplos critérios são analisados, tendo o transporte de forma implícita e explícita um papel relevante, por representar um catalisador de transformações no espaço urbano e regional. A acessibilidade desempenha então, um papel importante nas decisões locacionais, por possibilitar a ampliação do número de consumidores, por expandir mercados, por aumentar a eficiência da distribuição de produtos e por permitir a um número maior de trabalhadores atingirem os locais de trabalho.

Em seus estudos sobre economia espacial, Fujita et al. (2002) analisaram as consequências de duas ideias articuladas entre si. A primeira, de que os rendimentos crescentes e baixos custos de transportes tendem a criar uma lógica de aglomeração de atividades (forças centrípetas) e a segunda, de que devido à imobilidade de alguns recursos como terra e mão de obra, e a ocorrência de externalidades, como congestionamentos ou outras deseconomias, ocorrem forças que reagem a essa tendência (forças centrífugas). Do embate dessas duas forças opostas que moldam a estrutura espacial da economia, pode-se inferir pela transitoriedade dos ganhos de mobilidade e pelo caráter cíclico do processo de concentração e dispersão das atividades econômicas nos territórios.

No entanto, a visão tradicional da localização das empresas baseada em critérios clássicos de minimização dos custos de produção tem evoluído ao longo do tempo. As razões de localização para acesso a mercados ou fornecedores têm ampliado suas variáveis de análise, passando a incluir, a captação de externalidades, como uma estrutura urbana densa com economia de aglomeração, ou a presença de um polo tecnológico. Desta forma, as empresas evoluem de uma estratégia de localização para uma estratégia de ancoragem territorial (PECQUEUR e ZIMMERMANN, 2005).

Apesar da noção do crescimento polarizado ter dominado o planejamento regional em vários países, o conceito de polo de desenvolvimento ultrapassa a análise de Alfred Weber baseada na minimização dos custos de transportes, incorporando nas avaliações as relações intermediárias, que têm como fundamento teórico o modelo de Leontief (FUJITA ET AL, 2002). A aglomeração de empresas em polos passa a produzir economias externas, que representam ganhos gerados externamente às empresas, independentemente de sua atuação específica. Segue-se a esse fenômeno também a polarização humana e a diversidade cultural, decorrente da concentração de trabalhadores, de técnicos e de empreendedores (SOUZA, 2009), fazendo com que a con- corrência nos tempos atuais dependa da produtividade geral, e não do acesso a uma rede de insumos materiais ou da economia de escala de empreendimentos isolados, mas das condições do ambiente empresarial local (SATO, 2002).

Nesse contexto, a dinamização econômica da região beneficiada pela duplicação da BR-232-PE pode ter decorrido não apenas de questões relativas aos ganhos de tempo de viagem, mas também de externalidades devidas a situações preexistentes de concentração econômica em cidades líderes.

\section{O CASO EM ANÁLISE}

A BR-232-PE, com 553,2 km de extensão, atravessa o Estado de Pernambuco no sentido leste-oeste, desde o Recife até Parnamirim, onde se conecta com a BR-316. A BR232-PE, somada às outras rodovias secundárias que nela se conectam, atende às viagens, com destino à Região Metropolitana do Recife, dos residentes em cerca de $65 \%$ dos municípios de Pernambuco, o que abrange $42 \%$ da população e 26\% do PIB do Estado.

No final dos anos 1990, intensos congestionamentos e elevados índices de acidentes (897 acidentes com 52 mortos em 1998) alertavam para a necessidade da duplicação dos primeiros $150 \mathrm{~km}$ da rodovia. Nesse segmento o volume de tráfego diário vinha crescendo a mais de 5\% ao ano e já superava a 11.000 veículos no ano de 1997 . No começo de 2001 iniciam-se as obras de duplicação, tendo sido concluídas no final de 2004. Atualmente o tráfego médio diário é da ordem de 35.000 veículos, operando a velocidade média de $90 \mathrm{~km} / \mathrm{h}$ e em nível de serviço entre A e B.

O segmento duplicado nesta fase atravessa um território que compreende 11 municípios da Região Metropolitana do Recife, da Zona da Mata e do Agreste Pernambucano. Para efeito dos estudos de impactos econômicos diretos foram suprimidos os municípios da região metropolitana, por estarem submetidos a outra dinâmica dificultando a separação das causas, e acrescidas todas as cidades localizadas a até $50 \mathrm{~km}$ do eixo duplicado, totalizando desta forma, um conjunto de 28 municípios (ver Figura 1), que abrange uma população de cerca de 1.100 .000 habitantes (CONDEPE/FIDEM, 2004), equivalente a 13,2\% da população de Pernambuco.

Sob o aspecto econômico, em 2004 a região em análise apresentava PIB per capita equivalente a $85 \%$ da média de Pernambuco. Com relação ao Índice de Desenvolvimento Humano Médio (IDHm), que considera em conjunto indicadores de longevidade, renda e educação, em 2000 a região apresentava valor equivalente à média do Estado $(0,445)$. O setor econômico que em média mais emprega trabalhadores formais é a administração pública com 20,6\% dos empregos (nos pequenos municípios atinge até 60\%), seguidos do comércio com $17,3 \%$, dos serviços com $11,4 \%$ e da indústria (com predomínio de alimentos, têxtil e confecções) com 17,1\%. Observa-se ainda na região, uma grande concentração de empregos e empresas nas maiores cidades, Caruaru, Vitória de Santo Antão e Gravatá.

A área de comparação com 20 municípios e população de 535.000 habitantes (CONDEPE/FIDEM, 2004) representava 6,4\% da população de Pernambuco. Apesar de menos populosa, apresentava em 2004, PIB per capita de cerca de $90 \%$ da média dos municípios da BR-232 e o 


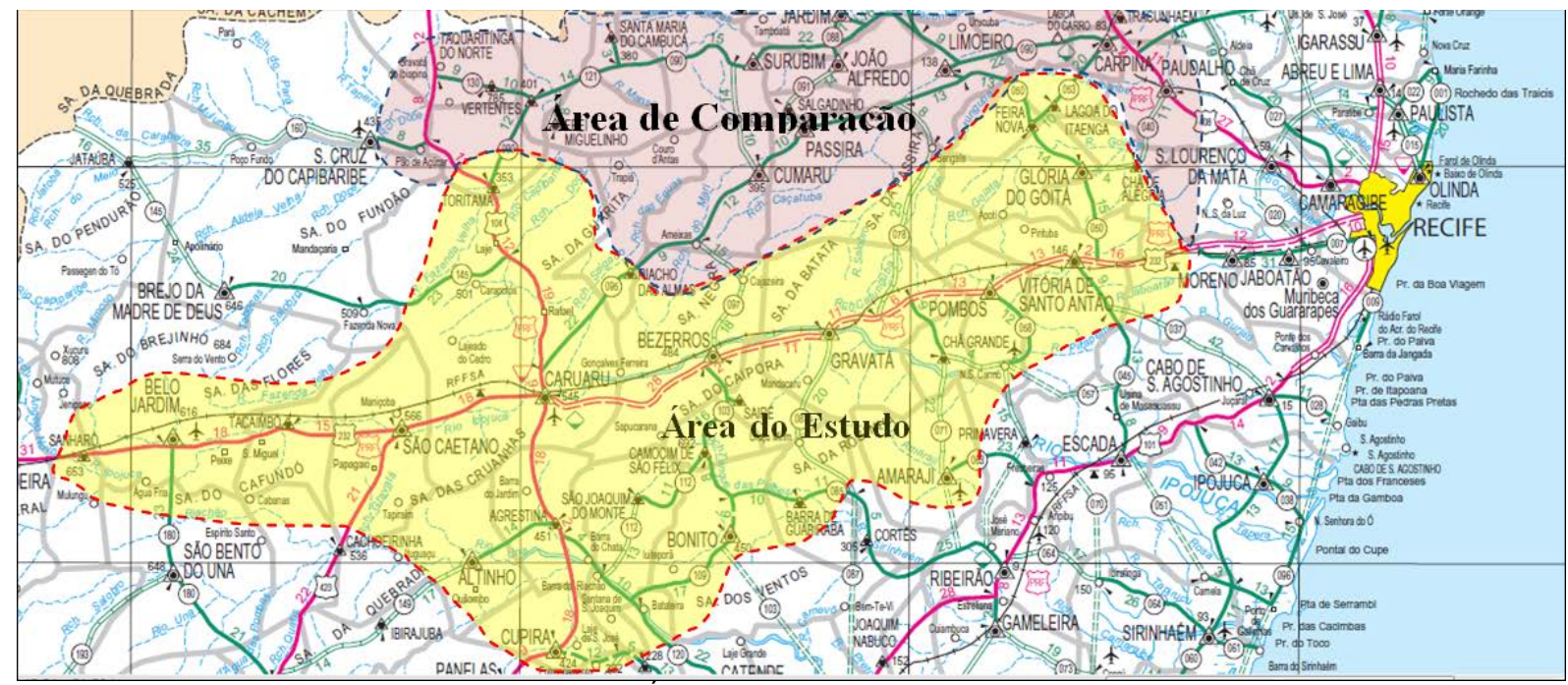

Figura 1. Áreas de estudo e de comparação

mesmo IDHm, demonstrando que não há diferenças significativas entre os perfis socioeconômicos das duas regiões que inviabilizem as análises comparativas.

\section{MÉTODO DE ANÁLISE}

Para testar os efeitos do investimento na duplicação da BR-232-PE inicialmente foi adotado um método baseado em um modelo comparativo de desempenho (EDRG, 2001), que se assenta em comparações da evolução de indicadores socioeconômicos, entre a área beneficiada e uma área de controle, considerando um período anterior às obras (19982003) e o pós obras (2004 a 2010). Para compor os indicadores foram utilizados dados secundários em painel relativos ao PIB municipal, população, empregos formais, salários, número de empresas, consumo de energia e receitas correntes municipais. Com esse método comparativo, desde que se evidenciem diferenças significativas de desempenho, pode-se sugerir relação direta entre o investimento realizado e o crescimento gerado, desde que não atuem outras variáveis, que no conjunto possam promover reações desiguais.

Considerando que o método comparativo foi testado sobre indicadores médios da região, fica ainda a necessidade de quantificar os efeitos de forma separada por município na área beneficiada e associá-los aos ganhos de tempo de viagem, tidos como utilidade essencial ao investimento em infraestrutura de transportes. Para tanto, adotou-se um modelo econométrico baseado em uma função de produção, que procurou quantificar a sensibilidade do crescimento médio do PIB municipal no período 2004 a 2010, deduzido do crescimento médio do PIB da área de comparação (para obter o efeito líquido), em relação aos benefícios decorrentes da redução dos tempos médios das viagens produzidas e atraídas por município e distribuídas por todo o Estado a partir de um modelo gravitacional. As estimativas dessas reduções de tempo foram obtidas por pesquisas de velocidade nos diversos trechos da rede rodoviária e por contagens dos fluxos de entrada e saída das cidades em 2010, comparados com estimativas das gerações de viagens em 2003, obtidas pelos valores médios de regressões lineares com variáveis de população, empregos e frota de veículos, e por velocidades estimadas nos diversos segmentos rodoviários, obtidas com base na metodologia do HCM 2000 (TRB, 2000).

\section{RESULTADOS}

Os resultados são apresentados em duas seções: a primeira trata de análises regionais realizadas por método comparativo e a segunda, se refere a análises econométricas em nível local entre os municípios beneficiados.

\subsection{Análise comparativa regional}

Com relação à evolução comparativa do tráfego rodoviário entre a rodovia que recebeu melhoramentos e outra rodovia de função equivalente na mesma região, mas que não recebeu melhoramentos no período, a Figura 2 demonstra equivalências entre as taxas de crescimento do tráfego nos anos anteriores à obra. Entretanto, observa-se que após a conclusão da duplicação em 2004, o tráfego diário da BR232-PE passou a crescer anualmente quase 2\% acima do tráfego da BR-408-PE. Essa constatação aponta o primeiro efeito diferencial da área beneficiada pelo investimento em relação à área de comparação, embora apenas a evolução do tráfego isoladamente possa não configurar uma relação de causalidade do crescimento, já que poderia ter decorrido também do tráfego desviado pela melhor condição da rodovia.

Ainda utilizando o Método Comparativo de Desempenho, a duplicação da BR-232-PE, com abertura ao tráfego em 2004, demonstra através da evolução de indicadores tais como, PIB municipal, crescimento da população, da massa salarial, do emprego, das empresas e do consumo de energia, que o conjunto dos municípios diretamente beneficiados apresentou crescimento superior ao observado na média do Estado de Pernambuco (2004 a 2010) e ao ocorrido em um conjunto de 20 municípios na mesma região, mas não beneficiados pelo investimento (ANDRADE, 2012).

Como indicador síntese desse crescimento diferenciado, a Figura 3 apresenta a evolução do PIB municipal entre 2002 e 2010, estimado em Pernambuco pela Agência CONDEPE/FIDEM desde 2002, segundo método do IBGE (2004), da região diretamente beneficiada em contraposição TRANSPORTES v. 23, n. 2 (2015), p.90-99 


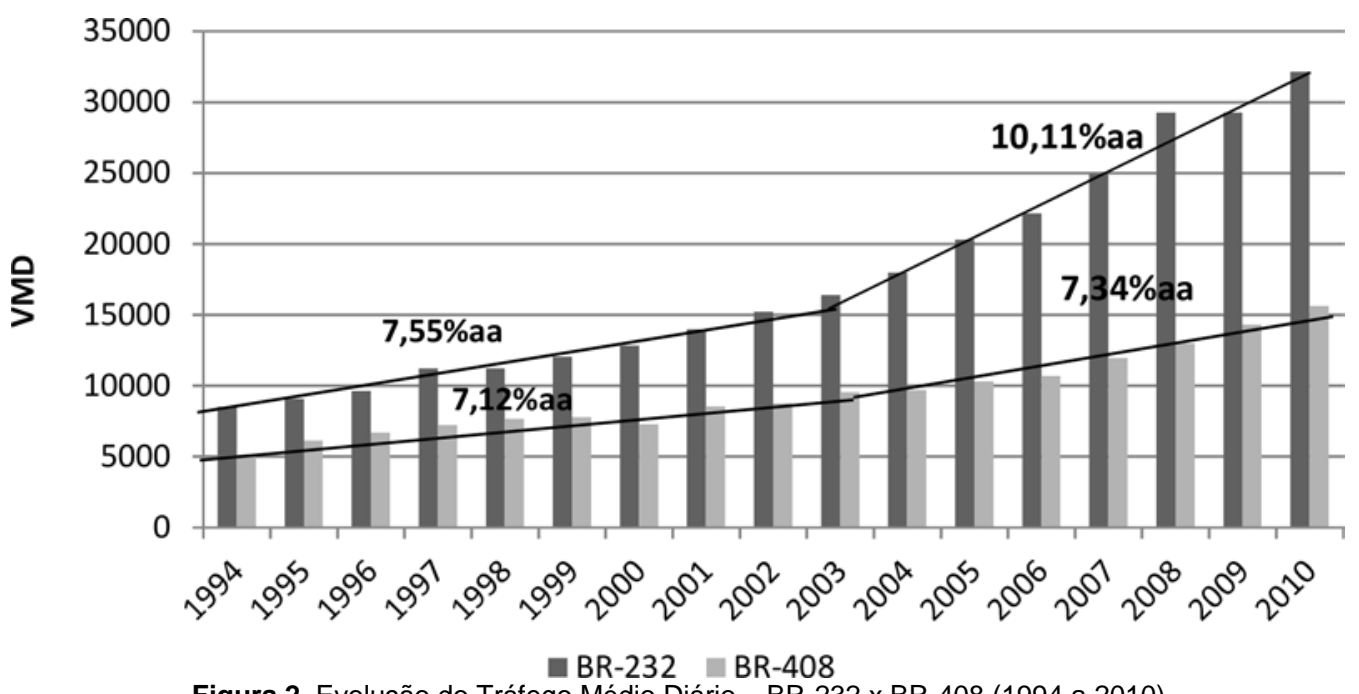

Figura 2. Evolução do Tráfego Médio Diário - BR-232 x BR-408 (1994 a 2010)

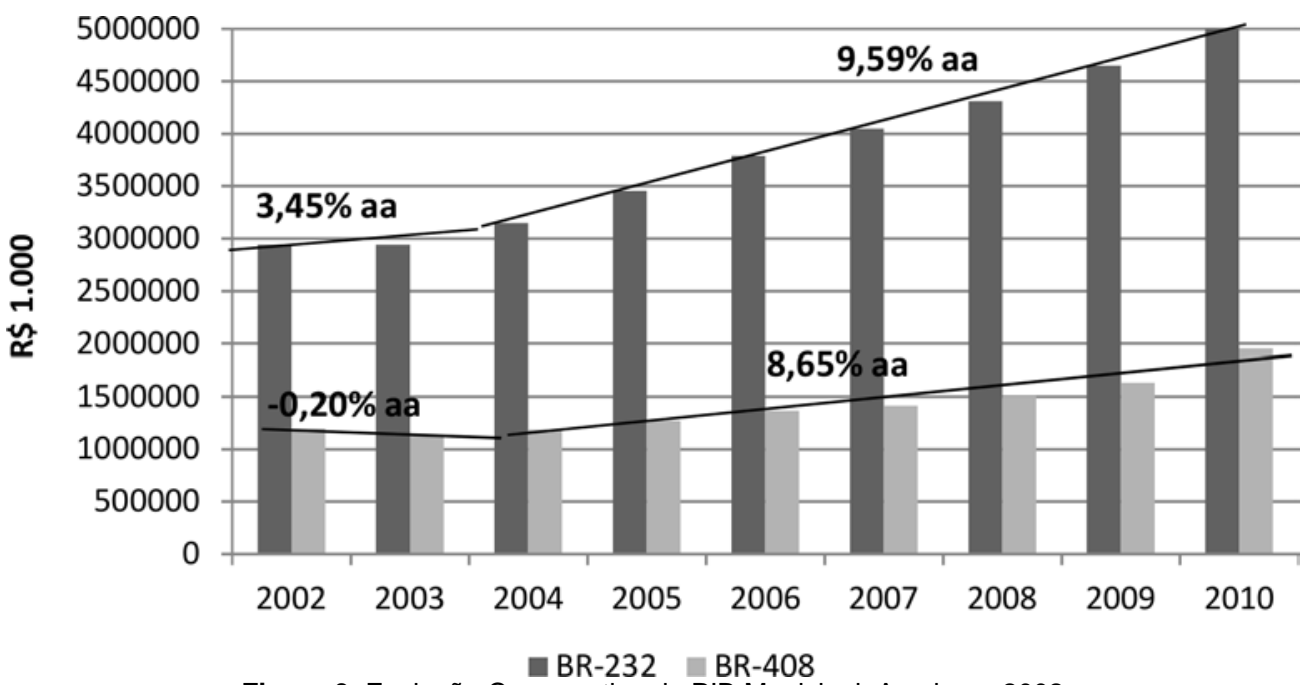

Figura 3. Evolução Comparativa do PIB Municipal. Ano base 2002

à região de comparação. Na fase de execução (2002 - 2004) um crescimento anual de 3,45\% já se manifestava influenciado provavelmente pelos dispêndios locais da obra e por outros investimentos devidos às expectativas positivas geradas. Após a abertura ao tráfego em 2004, a primeira região apresentou uma taxa de crescimento médio anual de 9,59\% e a segunda região de $8,65 \%$, sugerindo uma maior intensidade dos efeitos ex post de dinamização econômica. Chama-se a atenção para o fato de que a taxa de crescimento da região beneficiada também ter superado as taxas médias de crescimento do Estado de Pernambuco (8,3\%) e do Brasil (5,8\%).

A população da área beneficiada apresentou crescimento de 7,09\%, enquanto que, a da área de comparação cresceu 4,01\% (CONDEPE/FIDEM, 2010). Segundo dados do Ministério do Trabalho e Emprego (MTE), o número de empregos formais no setor privado nos municípios beneficiados cresceu no período $10,18 \%$, superando a área de comparação e a média do Estado, que aumentaram em 5,51\% e 7,85\%, respectivamente. A massa salarial evoluiu na área beneficiada a uma taxa anual de $14,37 \%$ comparada a 11,91\% na área de controle, embora esses ganhos não tenham se refletido na elevação do salário médio que cresceu $4,15 \%$, enquanto que na área de comparação evoluiu em 12,24\%. A abertura de novas empresas também diferencia a área da BR-232-PE, que apresentou crescimento no período de $5,42 \%$, superando as taxas da região de comparação (3,85\%) e do Estado de Pernambuco (3,11\%). Outro indicador importante que revela o nível diferenciado de atividade econômica é o consumo de energia elétrica industrial, comercial e rural, que, no período, apresentou crescimento de $41,31 \%$ na região beneficiada, enquanto cresceu $32,57 \%$ na região de comparação e 27,78\% no Estado.

É importante destacar, sobre as evidências da importância do investimento rodoviário para o crescimento observado, que no período analisado as condições de oferta das demais infraestruturas que têm condições de potencializar o crescimento regional (água, energia e comunicações) e dos serviços sociais básicos (saúde e educação) eram equivalentes nas duas regiões comparadas.

Além da não elevação do salário médio - a taxa anual de crescimento a preços correntes no período 2004-2010 com base em dados do MTE da região da BR-232-PE de $11,99 \%$ foi ligeiramente inferior à taxa da região de comparação (12,11\%), outra exceção foi a não captura pelas finanças municipais dos ganhos decorrentes da dinamização econômica produzida pelo investimento. A evolução média anual das receitas correntes municipais no período foi praticamente igual, sendo de $9,93 \%$ na região beneficiada e de 9,83\% na região de comparação. 


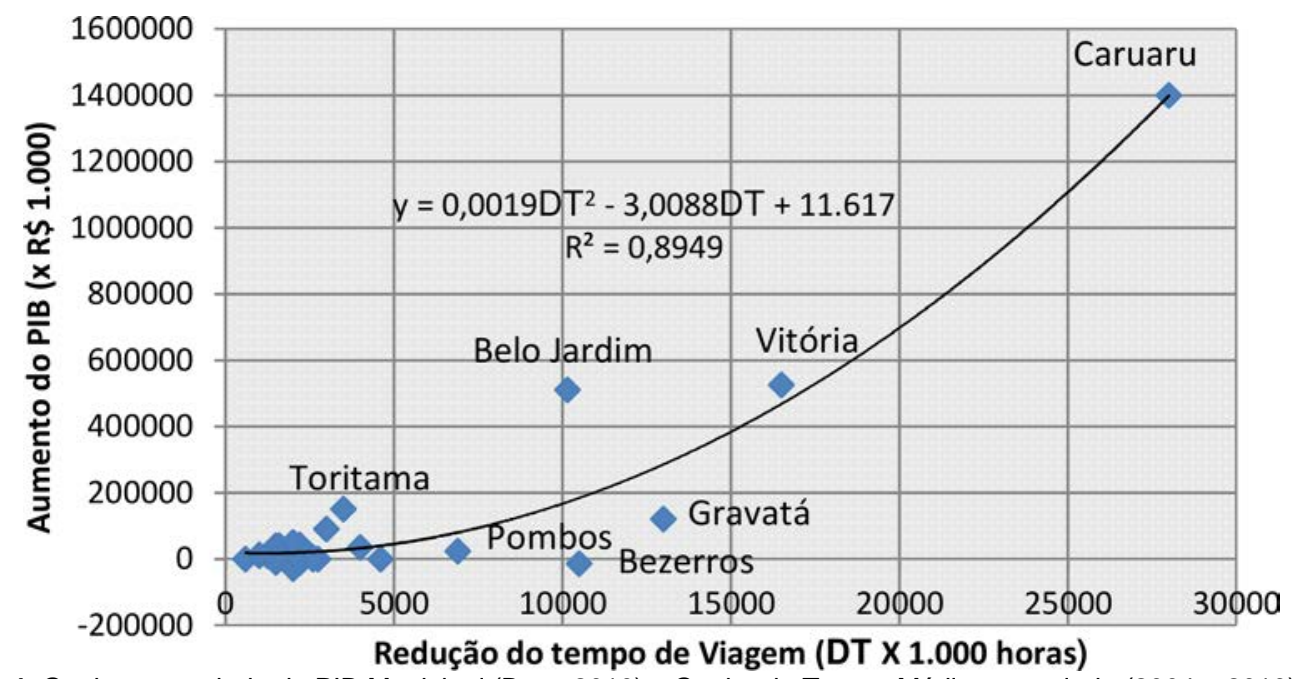

Figura 4. Ganho acumulado do PIB Municipal (Base 2010) x Ganho de Tempo Médio acumulado (2004 a 2010)

Tabela 1. Produtividades média e marginal do fator ganho de tempo sobre o PIB Municipal (2004-2010)

\begin{tabular}{|c|c|c|c|c|}
\hline Redução de Tempo de Viagem (T) & $\begin{array}{l}\text { Aumento do } \\
(P I B) \\
R \$ \times 10^{3}\end{array}$ & $\begin{array}{l}\text { Produtiv. } \\
\text { média } \\
\text { PIB/T }\end{array}$ & $\begin{array}{l}\text { Produtiv. } \\
\text { marginal } \\
\triangle P I B / \triangle T\end{array}$ & $\begin{array}{l}\text { Elasticid. do } \\
\text { produto } \\
\triangle \% P I B / \triangle \% T\end{array}$ \\
\hline $\begin{array}{l}\text { De } 1.000 \text { a } 2.500 \text { x } 10^{3} \text { horas } \\
16 \text { cidades c/ Pop. } 10.000 \text { a } 23.000 \text { hab. }\end{array}$ & 15.970 & 6,95 & 3,64 & 0,35 \\
\hline $\begin{array}{l}\text { De } 2.501 \text { a } 5.000 \text { x } 10^{3} \text { horas } \\
5 \text { cidades c/ Pop. } 23.001 \text { a } 35.000 \text { hab. }\end{array}$ & 15.970 & 7,21 & 11,24 & 1,76 \\
\hline $\begin{array}{l}\text { De } 5.001 \text { a } 10.000 \text { x } 10^{3} \text { horas. } \\
\text { Pombos ( } 25.000 \text { hab.) }\end{array}$ & 109.146 & 12,79 & 25,49 & 2,89 \\
\hline $\begin{array}{l}\text { De } 10.001 \text { a } 15.000 \text { x } 10^{3} \text { horas. } \\
\text { Belo Jardim, Bezerros e Gravatá ( } 50.000 \text { a } 80.000 \\
\text { hab.) }\end{array}$ & 293.602 & 21,67 & 44,49 & 2,59 \\
\hline $\begin{array}{l}\text { De } 15.001 \text { a } 20.000 \text { x } 10^{3} \text { horas } \\
\text { Vitória de Santo Antão ( } 130.000 \text { hab.) }\end{array}$ & 573.058 & 30,9 & 63,49 & 2,41 \\
\hline $\begin{array}{l}\text { De } 25.000 \text { a } 28.000 \text { x } 10^{3} \text { horas. } \\
\text { Caruaru } 320.000 \text { hab. }\end{array}$ & 1.033 .806 & 47,78 & 94,84 & 2,11 \\
\hline
\end{tabular}

\subsection{Análises econométricas locais}

Os resultados no período, resumidos na Tabela 1, a partir de uma função de produção tendo como variável explicada o aumento diferencial do PIB municipal e a variável explicativa a redução agregada do tempo médio de viagem, demonstram produto total e produtividades média e marginal crescentes com o porte das cidades, caracterizando um quadro de retorno crescente de escala. A elasticidade do produto apresenta inicialmente valores que caracterizam baixa elasticidade para economias de tempo nos municípios com até 23.000 habitantes, cresce com o aumento da população atingindo um pico em torno de uma população entre 35.000 e 50.000 habitantes e depois decresce suavemente, mas mantendo ainda elasticidades acima de 2 .

Pelos maiores volumes de viagens associados ao aumento da velocidade média, a função com produtividade marginal crescente demonstra que um ganho absoluto de PIB de R\$ 1 milhão (entre 2004 e 2010) foi obtido com uma economia média de tempo de viagem de 10.526 horas em Caruaru, 22.471 horas em municípios com população entre 50.000 e 80.000 habitantes e 274.725 horas nos 16 municípios menos populosos. As elasticidades do produto demonstram que para cada $1 \%$ de variação no ganho de tempo, o PIB municipal cresceu em média 2,11\% em Caruaru, 2,59\% em Belo Jardim, Bezerros e Gravatá e apenas $0,35 \%$ nas 16 menores cidades da região. Esses resultados demonstram que as cidades médias apresentam maior sensibilidade ao ganho de tempo do que Caruaru, a maior cidade da região, enquanto que as menores cidades apresentam resultados inelásticos em relação aos ganhos de tempo.

Utilizando-se outras funções de produção com a mesma variável independente e como variáveis dependentes separadamente, a criação diferencial de empregos e de empresas, verificou-se a criação de 3.300 novas empresas e a geração de 20.000 empregos privados entre 2004 e 2010 em relação ao crescimento médio da área de comparação. Destas novas empresas e empregos, cerca de 50\% concentra-se em Caruaru, que juntamente com Vitória de Santo Antão, Gravatá, Belo Jardim e Toritama e demais municípios mais industrializados, totalizam $87 \%$ das novas empresas e empregos, demonstrando que as novas condições de mobilidade atuaram para a consolidação dos polos de desenvolvimento pré-existentes. A maioria dos pequenos municípios periféricos, com população abaixo de 35.000 habitantes apresentou certa indiferença, com pequenas perdas ou ganhos insignificantes de empregos, com exceção dos municípios de Pombos, Chã Grande, Sairé e São Caetano, 
diretamente atravessados pela BR-232-PE, que demonstraram maiores ganhos (7\% dos empregos gerados), devidos a melhor condição locacional.

\section{CONCLUSÕES}

O crescimento regional estimulado pela duplicação da BR-232-PE, por meio de comparações realizadas com o desempenho médio de outra região não beneficiada demonstra, sob vários enfoques, um impacto positivo do projeto sobre a região. Os principais diferenciais entre as regiões situam-se sobre o aumento do PIB, do número de novos empregos e empresas nos setores industriais e comerciais e da massa salarial, comprovando-se dessa forma, os efeitos sugeridos por Weisbrod e Reno (2009), de que projetos dessa natureza podem estimular a atividade econômica, por meio de efeitos indiretos, devidos às atividades das empresas supridoras e por efeitos induzidos, devidos ao aumento da renda agregada, da massa salarial e provavelmente do consumo das famílias.

Como também a região beneficiada cresceu em ritmo superior à média do Estado, observa-se que, de uma perspectiva externa, a melhoria da acessibilidade regional produziu como benefício uma maior atratividade para a área como um todo, e neste caso funcionaram com mais intensidade os vetores relativos à descentralização do desenvolvimento de Pernambuco.

Em função dessa concentração dos benefícios econômicos, fica clara a importância de se aprofundarem estudos para melhor compreender como elevações nos níveis das infraestruturas e sistemas de transportes podem ser utilizadas como ferramentas para a expansão das oportunidades de emprego e da renda, também em áreas estagnadas, preocupação essa também expressa por Eberts (2000).

Outra questão importante extraída da comparação entre regiões foi a de que os ganhos médios obtidos pela região beneficiada, a partir da melhoria na mobilidade regional, situam-se na evolução da produção agregada, não surtindo efeitos sobre a distribuição da renda, por não alterar o salário médio percebido pelos trabalhadores, nem sobre as receitas próprias arrecadadas pelos municípios. Conclui-se que o projeto rodoviário atua sobre a região, mas não tem o poder de mudar as relações de hierarquia funcional entre as cidades e entre as pessoas, pois não influencia na distribuição da riqueza gerada.

Mas ao se fazer uma leitura por dentro da área beneficiada vê-se que o desenvolvimento se centralizou em polos, em um processo de polarização humana e econômica, decorrente da concentração de trabalhadores, de técnicos e de empreendedores em poucas localidades, corroborando desta forma com as reflexões de Sato (2002).

A redução dos custos de transportes pela diminuição dos tempos de viagem e, em consequência, os retornos crescentes de escala, conduziram ao aumento da concentração econômica nas cidades líderes, pela ação das forças centrípetas que reforçam as economias de aglomeração, atuando para organizar o espaço geográfico pelas novas condições de acessibilidade regional propiciadas, corroborando, desta forma, com os conceitos da economia espacial apresentados por Krugman (1996), Fujita et al (2002) e Rodrigue (2009).
Ainda nesse contexto, observou-se que os benefícios não foram distribuídos equilibradamente entre as localidades. Verificou-se um fortalecimento maior nos municípios mais populosos, com economias mais dinâmicas e diversificadas e certa indiferença nos impactos nos municípios pequenos e periféricos, mesmo que em alguns, observou-se evidentes ganhos de mobilidade. Esta questão da assimetria do desenvolvimento, já havia sido levantada por Banister e Berechman (2000), quando sustentavam que melhoramentos em infraestruturas de transportes fortalecem a acessibilidade à cidade central, concentrando atividades e tornando o seu espaço mais especializado, ressaltando ainda, a importância das condições pré-existentes favoráveis de mercado e qualidade de mão de obra local para o crescimento econômico.

O evidente ganho de mobilidade observado na área, medido pelo aumento da velocidade média de viagem juntamente com o aumento dos fluxos de tráfego em cada localidade mostram que as melhores condições físicas e operacionais da rodovia duplicada facilitaram o intercâmbio entre localidades. No entanto, esse aumento de fluxo destinou maior quantidade de viagens para cidades que já apresentavam maior capacidade de atendimento das demandas regionais por compras, lazer, empregos, educação superior e de saúde. Vê-se dessa forma, que a melhoria da acessibilidade e da mobilidade tem pouca influência em promover, naturalmente, mudanças nas hierarquias funcionais entre as cidades. Sem que haja ações estratégicas eficientes de governo e políticas de incentivos a atividades produtivas, para tentar melhor distribuir os efeitos do projeto, a tendência é a manutenção do status quo.

Os benefícios do projeto por localidade variam em função dos ganhos auferidos na redução do tempo total de viagem em relação à situação anterior. Fica evidente, que localidades com maior potencial de geração de viagens e com maior utilização dos segmentos duplicados apresentaram ganhos mais expressivos, do que pequenos municípios periféricos à rede analisada.

Os municípios com maiores níveis de diversificação econômica situados nas margens da rodovia (Caruaru, Vitória de Santo Antão e Belo Jardim) apresentaram maiores ganhos no PIB, enquanto outros também atravessados pela BR-232-PE, como Bezerros, Gravatá e Pombos, situam-se abaixo da curva de produtividade, denotando a ocorrência de outros fatores influentes, como a concentração prévia de atividades econômicas mais produtivas nos polos regionais.

Os resultados com relação à criação de empregos e empresas reforçam a ocorrência do fenômeno do crescimento polarizado pela aglomeração de empresas, com aumento da produtividade geral pelos ganhos de escala e pelo aumento da diversidade de trabalhadores especializados nas cidades mais dinâmicas, convergindo para os conceitos da economia espacial sustentados por Sato (2002), Pecqueur e Zimmermann (2005) e Souza (2009). Os pequenos municípios mais distantes do eixo rodoviário duplicado que perderam empregos demonstram que o fenômeno do transbordamento teve efeito negativo (ANDRADE, 2012).

O caso da BR-232-PE corrobora com as reflexões de Banister e Berechman (2000), Princinote e Aragão (2009), e Boarnet (1995), em relação às condições e sinergias prévias, pois o investimento foi realizado em uma região com maior potencial de crescimento e que o crescimento diferencial nos anos seguintes pode ter sido causado por uma 
redistribuição do investimento produtivo entre regiões próximas, atuando aí o efeito negativo do transbordamento. De uma maneira geral, apesar da desigual distribuição dos benefícios entre os municípios, foram mais beneficiados os municípios que já detinham melhores condições econômicas em relação aos menos dinâmicos e os mais próximos ao eixo rodoviário duplicado, em relação aos periféricos atendidos por rodovias de ligação de classe inferior.

Dentre outras limitações que extrapolam as análises da desigualdade regional do crescimento econômico produzido, destacam-se:

1. A não captura pelas finanças municipais dos ganhos do aumento da atividade econômica local, decorrente provavelmente de deficiências nas estruturas de arrecadação dos pequenos municípios, da elevada participação da economia informal e da forte dependência das transferências do Fundo de Participação dos Municípios; e

2. A neutralidade na elevação do salário médio dos trabalhadores formais em relação à área de controle, que se deve provavelmente ao fato de que o crescimento do emprego e a abertura de novas empresas se basearam na geração de empregos de baixa remuneração em empresas em sua maioria, médias ou pequenas.

A duplicação da BR-232-PE poderia de outra forma apresentar retornos econômicos mais expressivos, caso na sua formulação estivesse associada a um programa de desenvolvimento territorial, com estímulo a projetos correlatos e complementares ao investimento público e com foco na sustentabilidade fiscal, conforme propõe Aragão (2009) nos fundamentos da Engenharia Territorial.

\section{REFERÊNCIAS}

Andrade, M., (2012). Efeitos da melhoria da mobilidade rodoviária sobre a economia local e regional: $\mathrm{O}$ caso da duplicação da BR-232/PE, Tese de Doutorado apresentada ao Programa de Pós-Graduação em Engenharia Civil da UFPE. Disponível em: http://www.repositorio.ufpe.br

Aragão, J. e Pricinote, M., (2009). Engenharia Territorial: Problemas e Territórios Programáticos, Textos para Discussão \# 8, Abril 2010, (CEFTRU), UNB.

Aschauer, D. A., (1989). Is Public Expenditure Productive? Journal of Monetary Economics, v. 23, p. 177-200.

Banister, D. e Berechman J. (2000). Transport Investment and Economic Development, UCL, London.

Boarnet, M., (1995). Highways and economic productivity: interpreting recent evidence. University of California Transportation Center, Working Paper \# 291.

CONDEPE/FIDEM (2010): Base de Dados do Estado (BDE), www.bde.pe.gov.br.

Eberts, R. (2000). Understanding the impact of transportation on economic development. Transportation in the New Millennium. Disponível em:

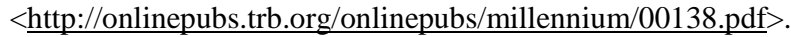
Acesso em: jul. 2012.
Estache, A. e Fay, M., (2007). Current Debates on Infrastructure Policy. Policy Research Working Paper 4410, DOI: 10.1596/1813-9450-4410

EDRG (2001). Using Empirical Information to Measure the Economic Impact of Highway Investments. Final Report, Volume 1: Review of Literature, Data Sources, and Agency Needs. Economic Development Research Group, Inc.: Boston, MA, EUA. Disponível em: http://www.edrgroup.com/pdf/fhwa-hwyimpact-vol-1.pdf. Acesso em junho de 2012

Ferreira, P.C., (1996). Investimento em Infraestrutura no Brasil: fatos estilizados e relações de longo prazo. Pesquisa e Planejamento Econômico, IPEA, Rio de Janeiro, v. 6, n. 2, p231-252, ago 1996. Disponível em: http://www.ppe.ipea.gov.br/ index.php/ppe/article/viewFile/756/696. Acesso em: abril de 2012.

Ferreira, P. C. e Malliagros, T. (1998). Impactos Produtivos da Infraestrutura no Brasil - 1950/95, Pesq. e Planej. Econ. IPEA, Rio de Janeiro ISSN 2237-2091. v. 28, n.2. p. 315-338, 1998. Disponível em: http://www.fgv.br/professor/ferreira/ ferreiramalliagrosPPE.pdf . Acesso em: agosto de 2012.

Fujita, M., Krugman, P. e Venables, A. (2002). Economia Espacial: Urbanização, prosperidade econômica e desenvolvimento humano no mundo. 391 p, Ed. Futura, São Paulo.

Horst, T.; e Moore, A. (2003). Industrial Diversity, Economic Development, and Highway Investment in Louisiana. Transportation Research Record, v. 1839, p. 136-141. DOI:10.3141/1839-15

IBGE, (2004). Produto interno bruto dos municípios 2004-2008. Disponível em: http://www.ibge.gov.br/home/estatistica/economia/pibmunicipios /2004_2008/.

Iacono, M.; e Levinson, D. M. (2008). Review of Methods for Estimating the Economic Impact of Transportation Improvements. Social Science Research Network, 16 p. DOI:10.2139/ssrn.1736116. Acesso em: fevereiro de 2012.

Krugman, P. (1996). Urban Concentration: The role of increasing returns and transportation cost. International Regional Science Review, v. 19, n. 1-2, p. 5-30.

DOI:10.1177/016001769601900202.

Litman, T. A.; e Doherty, E. (2009). Transportation Cost and Benefit Analysis Techniques, Estimates and Implications (2a. ed.). The Victoria Transport Policy Institute: Victoria, BC, Canadá. Disponível em http://www.vtpi.org/tca. Acesso em: maio 2012.

Martino A., Fiorello D., Zecca E., Ponti, M., Maffii, S. (2005). Assessment of the contribution of the TEN and other transport policy measures to the mid-term implementation of the White Paper on the European Transport Policy for 2010', European Commission - DEG TREN

Ozbay, K.; Ozmen-Ertekin, D.; e Berechman, J. (2007)

Contribution of transportation investments to county output. Transport Policy, v. 14, n. 4, p. 317-329.

DOI:10.1016/j.tranpol.2007.03.004

Pecqueur, B. e Zimmermann, J. B. (2005) Fundamentos de uma economia de proximidade, In: Clélio Diniz e Mauro Lemos (Eds) 
(Economia e Território), p.77-101, Editora UFMG, Belo Horizonte.

Queiroz, C. e Gautam, S., (1992). Road Infrastructure and Economic Development: Some Diagnostic Indicators, Working Paper 921, Transport - World Bank

Rodrigue, J.P., Contais, C. e Slack, B. (2009). The Geography of Transport Systems. 2a Edition, 352 p, Routledge. ISBN - 978-0415-82254-1, New York. Disponível em: https://people. hofstra.edu/geotrans/ Acesso em abril de 2012.

SACTRA - (Standing Advisory Committee on Trunk Road Appraisal), 1999: Transport and the Economy - Full Report, London.

Sato, F. R. (2002) Problemas e Métodos Decisórios de Localização de Empresas, RAE-eletrônica, ISSN 1676-5648, v. 1, n.2, jul-dez/2002.Fundação Getúlio Vargas, Escola de Administração de Empresas de São Paulo. Disponível em: http://www.redalyc.org/pdf/2051/205118144011.pdf Acesso em maio de 2012.

Singru, N., (2007). Socioeconomic Effects of Road Improvements, Program Evaluation for the Transport Sector in India- Asian Development Bank.

Smith, T. (1994) The impact of highway infrastructure on economic performance. Public Roads, v. 57, n. 4. Disponível em: https://www.fhwa.dot.gov/publications/publicroads/94spring/p94 sp8.cfm

Souza, N. de J., (2009). Desenvolvimento Econômico, 5a Edição Revisada, Editora Atlas, 313 pag.

Tong, T., (2013). Evaluating the contribution of infrastructure to U.S. Agri-Food Sector Output. Master's Thesis,

http://trace.tennessee.edu/utk_gradthes/1319. Acesso em julho de 2015.

TRB (2000). Highway Capacity Manual 2000. Chapter 12, II/III. Transportation Research Board, Washignton, DC, EUA.

Weisbrod, G. (2008). Models to predict the economic development impact of transportation projects: historical experience and new applications. Annals of Regional Science, v. 42, n. 3, p. 519-543. DOI: 10.1007/s00168-007-0184-9.

Weisbrod, G.; e Reno, A. (2009). Economic impact of public transportation investment (TCRP Project J-11, Task 7). American Public Transportation Association. Disponível em: http://reconnectingamerica.org/assets/Uploads/economicimpactof publictransportationinvestment.pdf 